\title{
Antibiotic-Based Conjugates Containing Antimicrobial HLopt2 Peptide: Design, Synthesis, Antimicrobial and Cytotoxic Activities
}

Natalia Ptaszyńska ${ }^{a *}$, Katarzyna Gucwa ${ }^{\text {a,b }}$, Katarzyna Olkiewicz ${ }^{a}$, Anna Łęgowska ${ }^{a}$, Joanna Okońska $^{a}$, Jarosław Ruczyńskia, Agata Gitlin-Domagalskaa, Dawid Dębowskia, Sławomir Milewski ${ }^{\mathrm{b}}$, Krzysztof Rolka ${ }^{\mathrm{a}}$

aDepartment of Molecular Biochemistry, Faculty of Chemistry, University of Gdańsk, Wita Stwosza 63, 80-308 Gdańsk, Poland

${ }^{b}$ Department of Pharmaceutical Technology and Biochemistry, Faculty of Chemistry, Gdańsk University of Technology, Narutowicza 11/12, 80-233 Gdańsk, Poland

*Corresponding author: natalia.ptaszynska@ug.edu.pl, tel: +48 5852350 92, fax: +48 58523 5012

\section{METHODS}

Solid-Phase Peptide Synthesis (SPPS). All peptides were obtained using the standard Fmoc chemistry solid-phase peptide synthesis (SPPS) utilizing an automatic Prelude peptide synthesizer ((Gyros) Protein Technology Inc., USA), and have been described previously. ${ }^{1}$ Peptides were synthesized on a 2-chlorotrityl chloride resin (substitution of $\mathrm{Cl}$ atoms 1.46 $\mathrm{mmolg}^{-1}, \mathrm{GL}^{\mathrm{B}} \mathrm{Bochem}$, Shanghai, China) or a RINK AMIDE MBHA resin (loading $0.78 \mathrm{meqg}^{-}$ ${ }^{1}$, Rapp Polymere, Germany) to obtain peptides with carboxyl or amide group on their $C$-termini after cleavage, respectively. In the case of $\boldsymbol{C} \boldsymbol{f}$-HLopt2, in the last step of the synthesis, peptidylresin with free $N$-terminal amino group was reacted with a mixture of 3 equiv. of 5(6)carboxyfluorescein (Novabiochem,) and 3 equiv. of HATU, HOAt, and DIPEA (molar ratio 1:1:1:2) in DMF, as described previously. ${ }^{2,3}$ All described peptides were removed from the resin in one-step procedure using a mixture of TFA:phenol:triisopropylsilane: $\mathrm{H}_{2} \mathrm{O}$ (88:5:2:5, v/v/v/v). The crude peptides were purified on PLC 2050 Gilson HPLC with Gilson Glider Prep. Software (Gilson, France), equipped with Grace Vydac C18 (218TP) HPLC column $(22 \times 250$ $\mathrm{mm}, 10 \mu \mathrm{m}, 300 \AA$ A, Resolution Systems). The solvent systems were $0.1 \%$ TFA in water (A) and $80 \%$ acetonitrile in A (B). Different linear gradients were applied (flow rate $20 \mathrm{mLmin}^{-1}$, monitored at $226 \mathrm{~nm}$ ). The purities of the synthesized peptides were checked with HPLC Pro

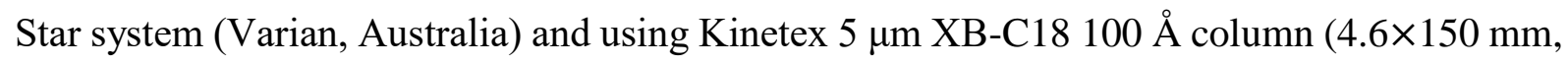
Phenomenex ${ }^{\circledR}$ ). The solvent system was as described above. Linear gradient from 10 to $90 \% \mathrm{~B}$ for $40 \mathrm{~min}$, flow rate $1 \mathrm{mLmin}^{-1}$, monitored at $226 \mathrm{~nm}$ was used. All described peptides had the purity of at least $95 \%$. In order to confirm the correctness of molecular masses of the synthesized peptides, mass spectrometry analysis was carried out using the MALDI-TOF MS (Biflex III MALDI-TOF spectrometer, Bruker Daltonics or MALDI TOF/TOF 5800+ 
spectrometer, AB SCIEX) with the $\alpha$-cyano-4-hydroxycinnamic acid (CCA) and/or 2,5dihydroxybenzoic acid (DHB) matrix. The HPLC, MS analyses, and total yields of all constituent peptides are summarized in Table 1 and in Supporting Information Figure S1 Additionally, the chemical structure of all conjugates were confirmed by UPLC/Q-TOF/MSMS analyses (Figure S2).

UPLC/Q-TOF/MSMS analyses were conducted on Agilent 6550 Q-TOF LC/MS with Agilent 1290 Infinity LC (Agilent Technologies). The chromatography was performed on ZORBAX Eclipse Plus C18 column (100×2.1 mm, 1,8-Micron). The column temperature was maintained at $24{ }^{\circ} \mathrm{C}$ and the flow rate for all of the experiments was $0.3 \mathrm{mLmin}^{-1}$. The mobile phase consisted of $0.1 \% \mathrm{HCOOH}$ in water (solvent $\mathrm{A}$ ) and $0.1 \% \mathrm{HCOOH}$ in $\mathrm{ACN}$ (solvent $\mathrm{B}$ ). Chromatographic separation was carried out with an linear gradient elution as follows: 0-5 min, 2-98\% B; 5-8 $\min , 2 \% \mathrm{~B}$. The automatic sampler was maintained at $24{ }^{\circ} \mathrm{C}$ and the injection volume was $1 \mu \mathrm{L}$. The mass spectra were acquired in positive mode with the mass to charge ratio $(\mathrm{m} / \mathrm{z})$ ranging from 100 to 2500 and acquisition rate $1 \mathrm{spectrum} / \mathrm{s}$. The MS conditions: dry gas temperature $250{ }^{\circ} \mathrm{C}$, dry gas $\left(\mathrm{N}_{2}\right)$ flow rate $12 \mathrm{Lmin}^{-1}$, nebuliser pressure $40 \mathrm{psi}$, sheath gas temp. $350{ }^{\circ} \mathrm{C}$, sheath gas flow $11 \mathrm{~L} / \mathrm{min}$, Vcap $3500 \mathrm{~V}$, nozzle voltage $2000 \mathrm{~V}$ and fragmentor voltage $175 \mathrm{~V}$. The energies for collision-induced dissociation (CID) were set at 10 and $20 \mathrm{eV}$. Experimental data were analysed using the Agilent MassHunter Workstation software - Qualitative Analysis (Version B.07.00, Agilent Technologies) using Find by Formula and Find by Targeted MS/MS algorithms. 
1. HLopt2- $\mathrm{NH}_{2}$

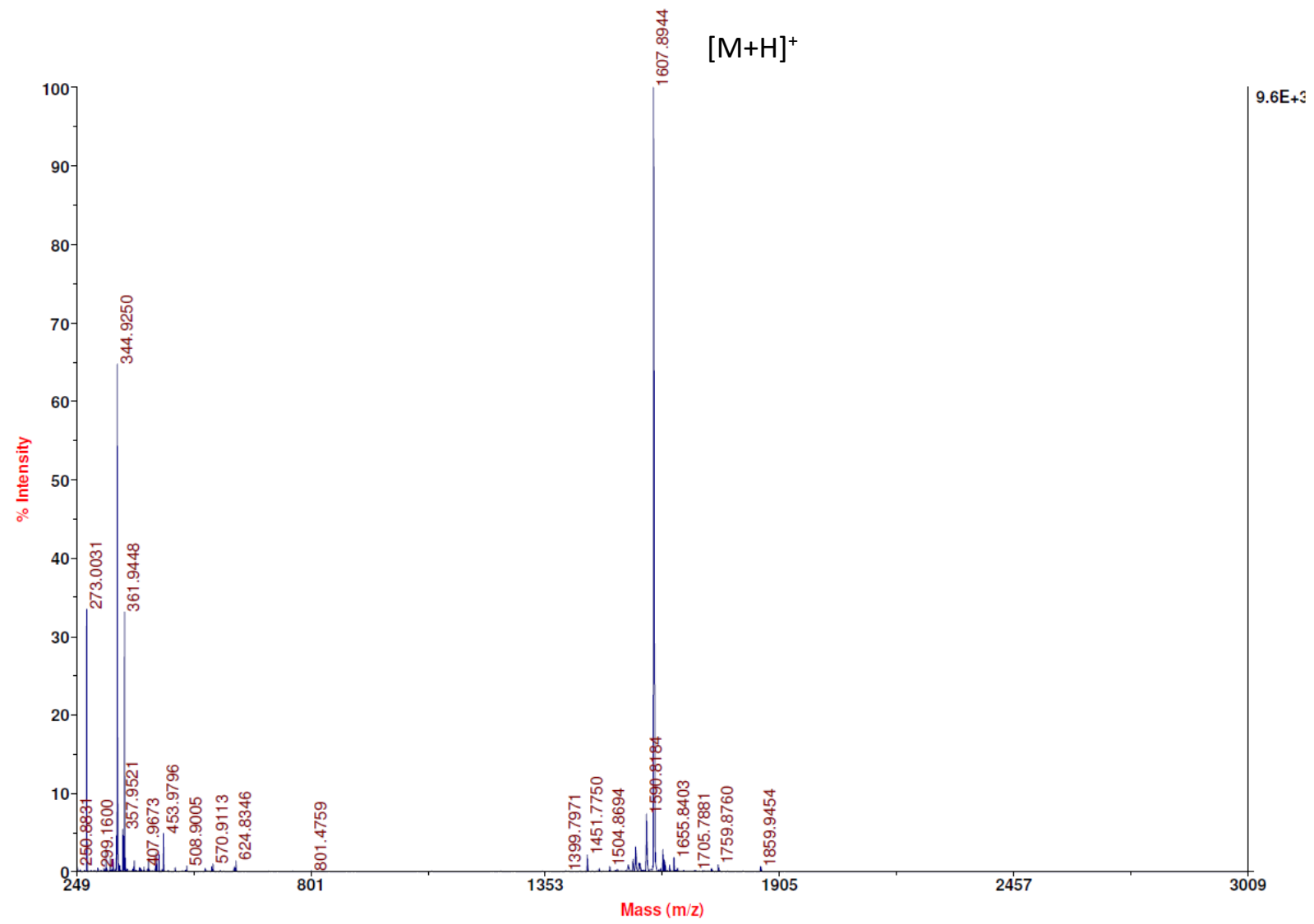

2. HLopt2

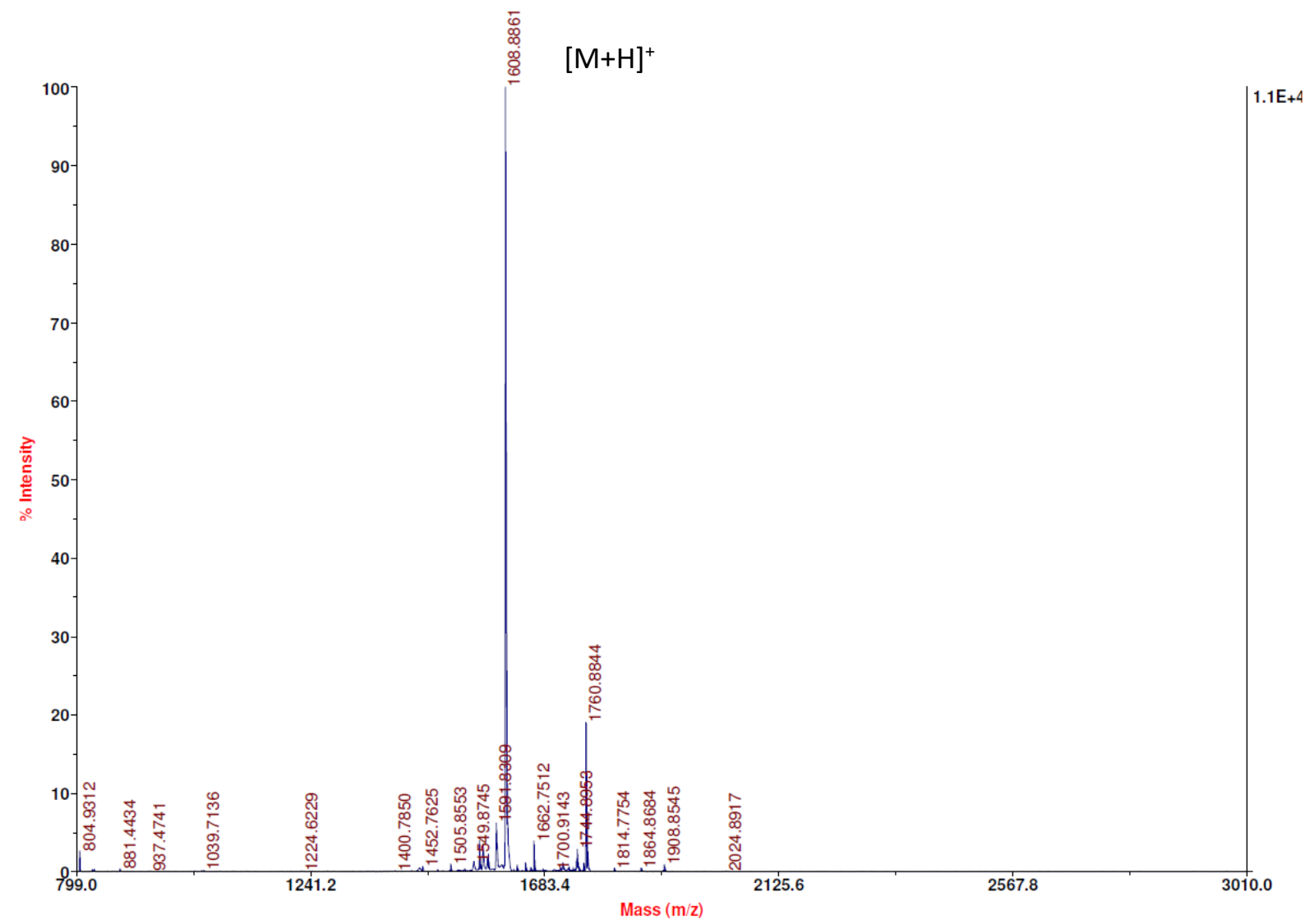


3. $\boldsymbol{C} \boldsymbol{f}$-HLopt2

$[\mathrm{M}+2 \mathrm{H}]^{+}$

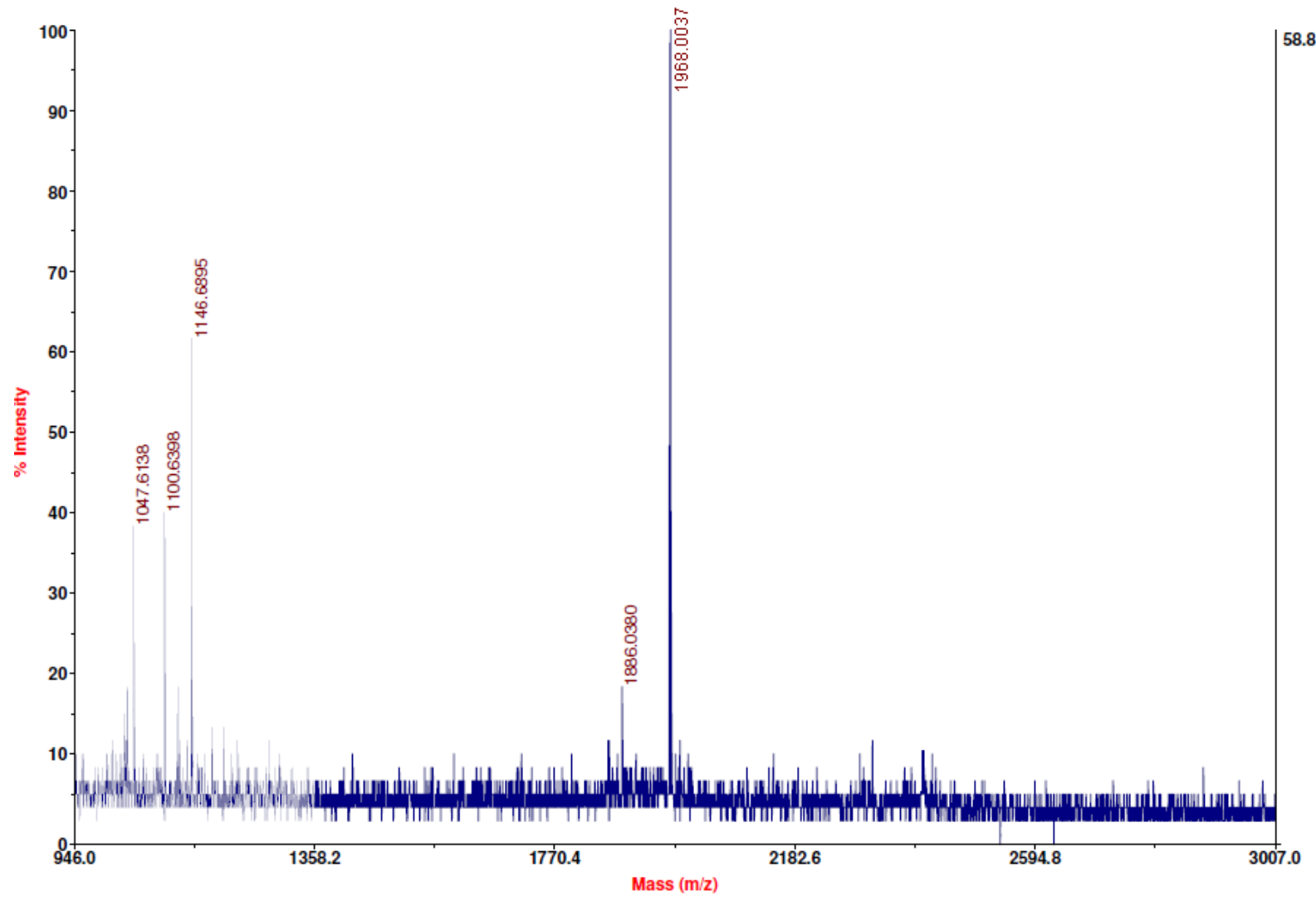

4. LVX-HLopt2-NH 2 (I)

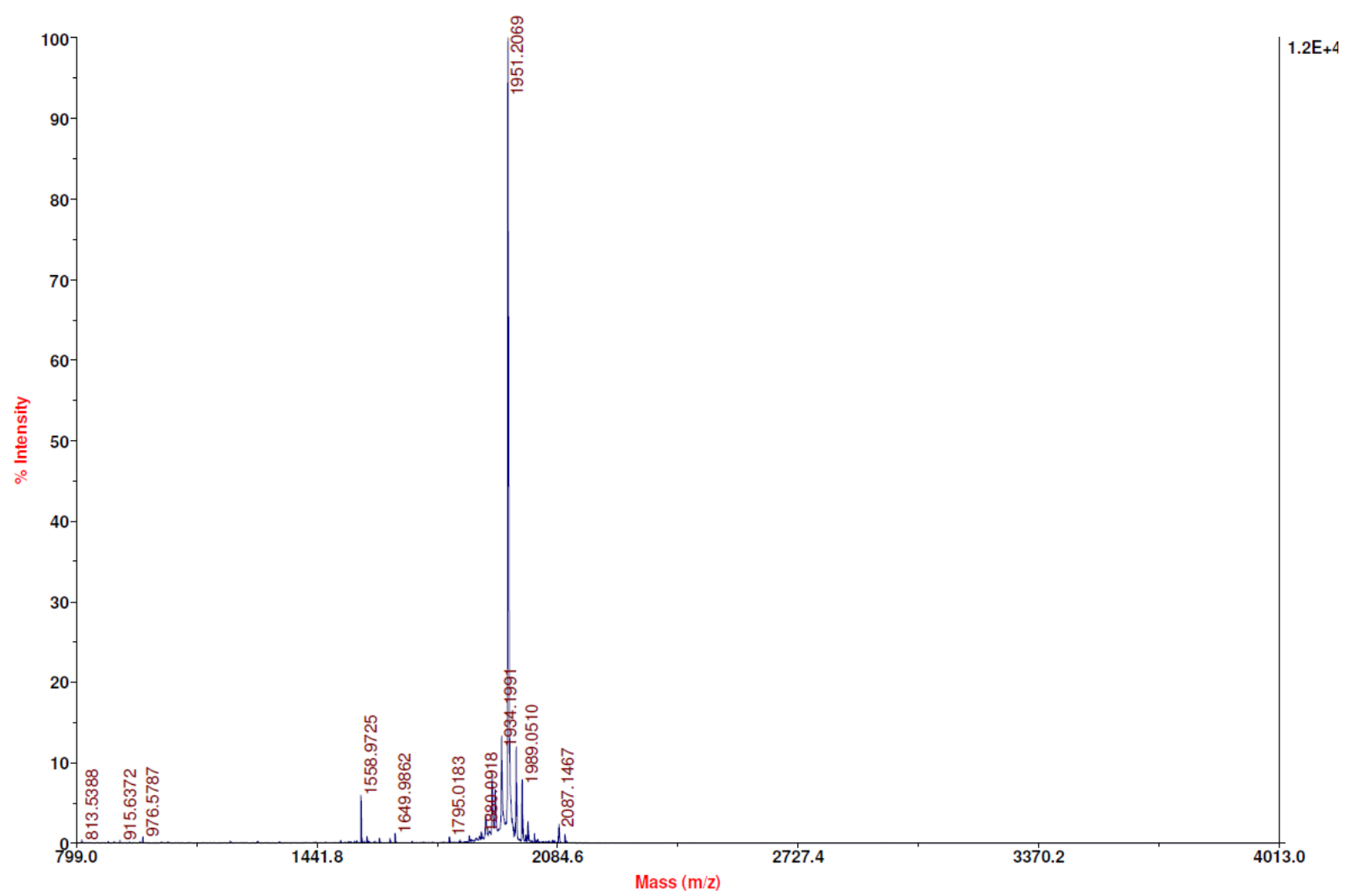


5. CIP-CH${ }_{2} \mathrm{CO}-\mathrm{HLopt} 2-\mathrm{NH}_{2}$ (II)

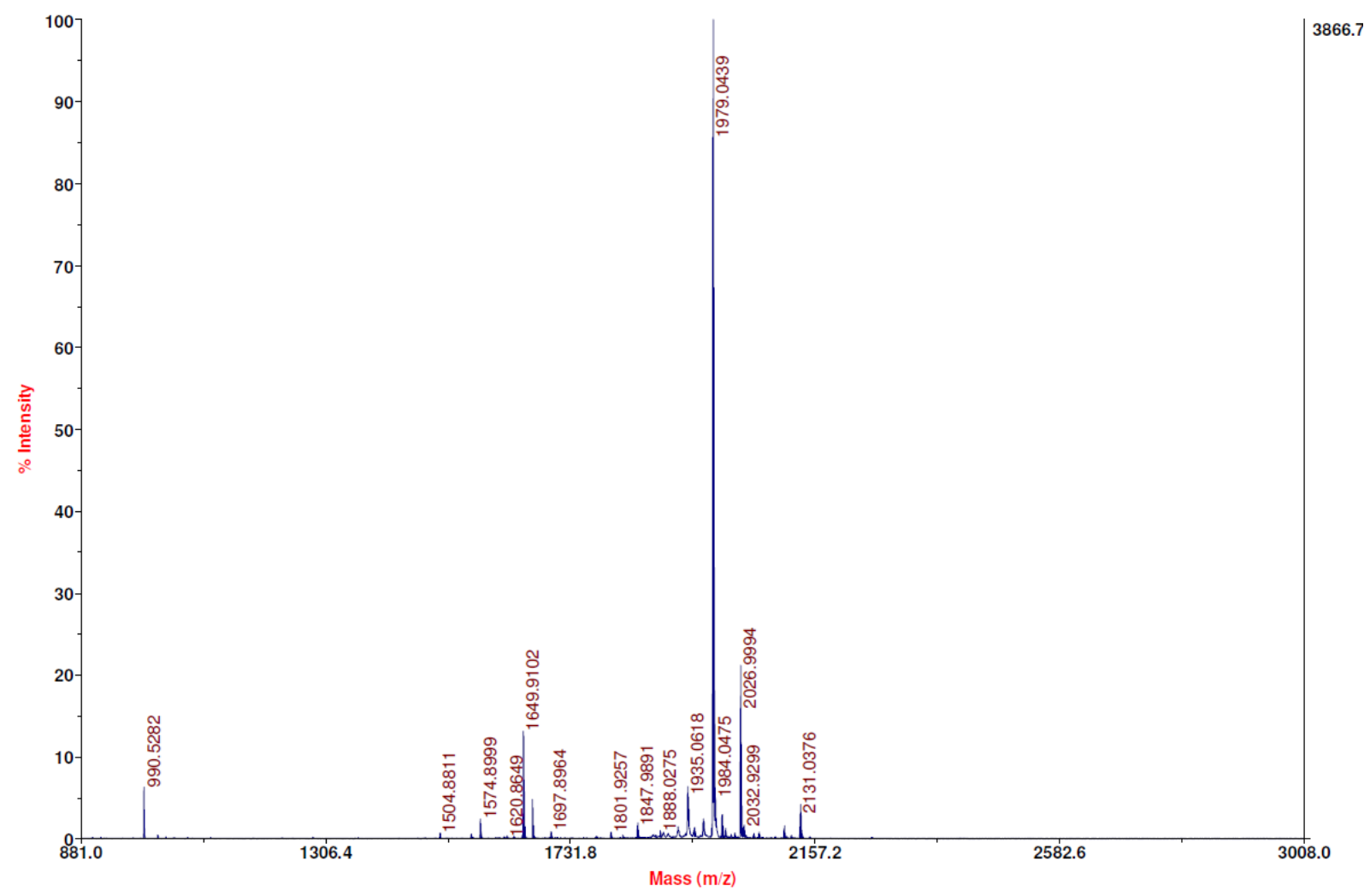

6. CIP-Cys-S-S-HLopt2-NH 2 (III)




7. CIP-Cys-S-S-Cf-HLopt2 (V)

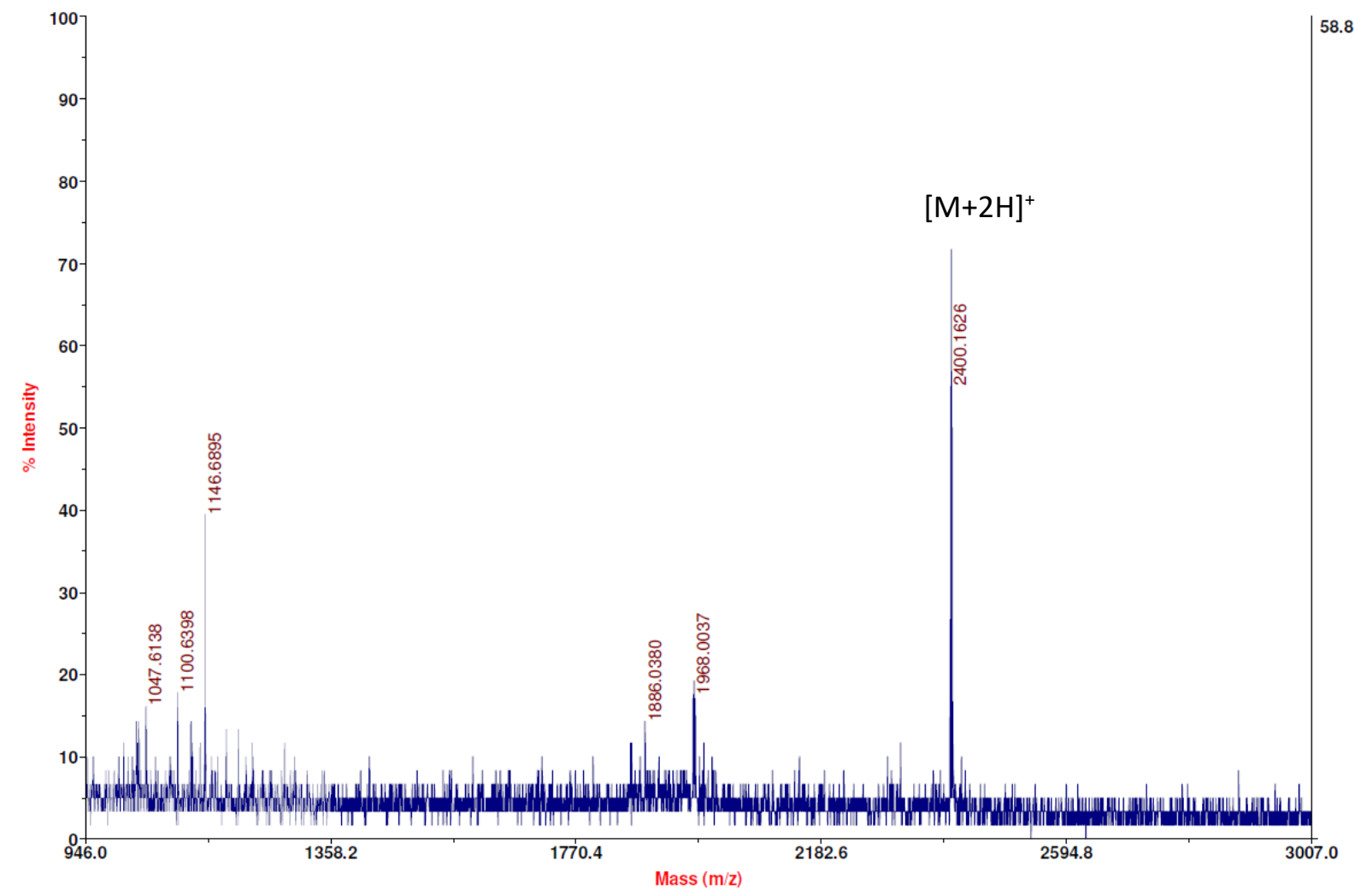

8. FLC-HLopt2- $\mathrm{NH}_{2}$ (IV)

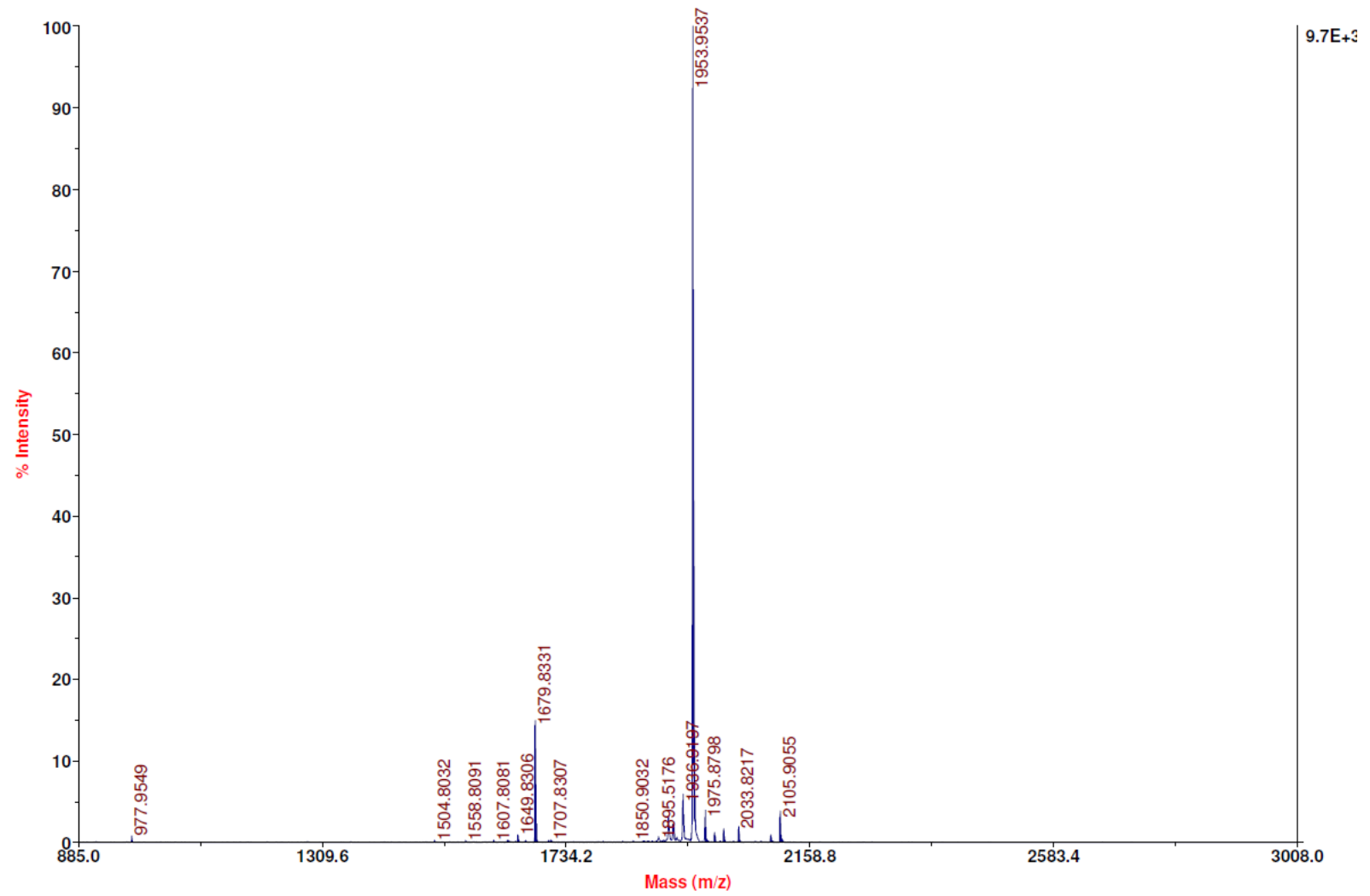

Figure S1. MS analyses of peptide and peptide conjugates. 
1. LVX-HLopt2-NH 2 (I)


C



2. CIP-CH $2 \mathrm{CO}-\mathrm{HLopt} 2-\mathrm{NH}_{2}$ (II)
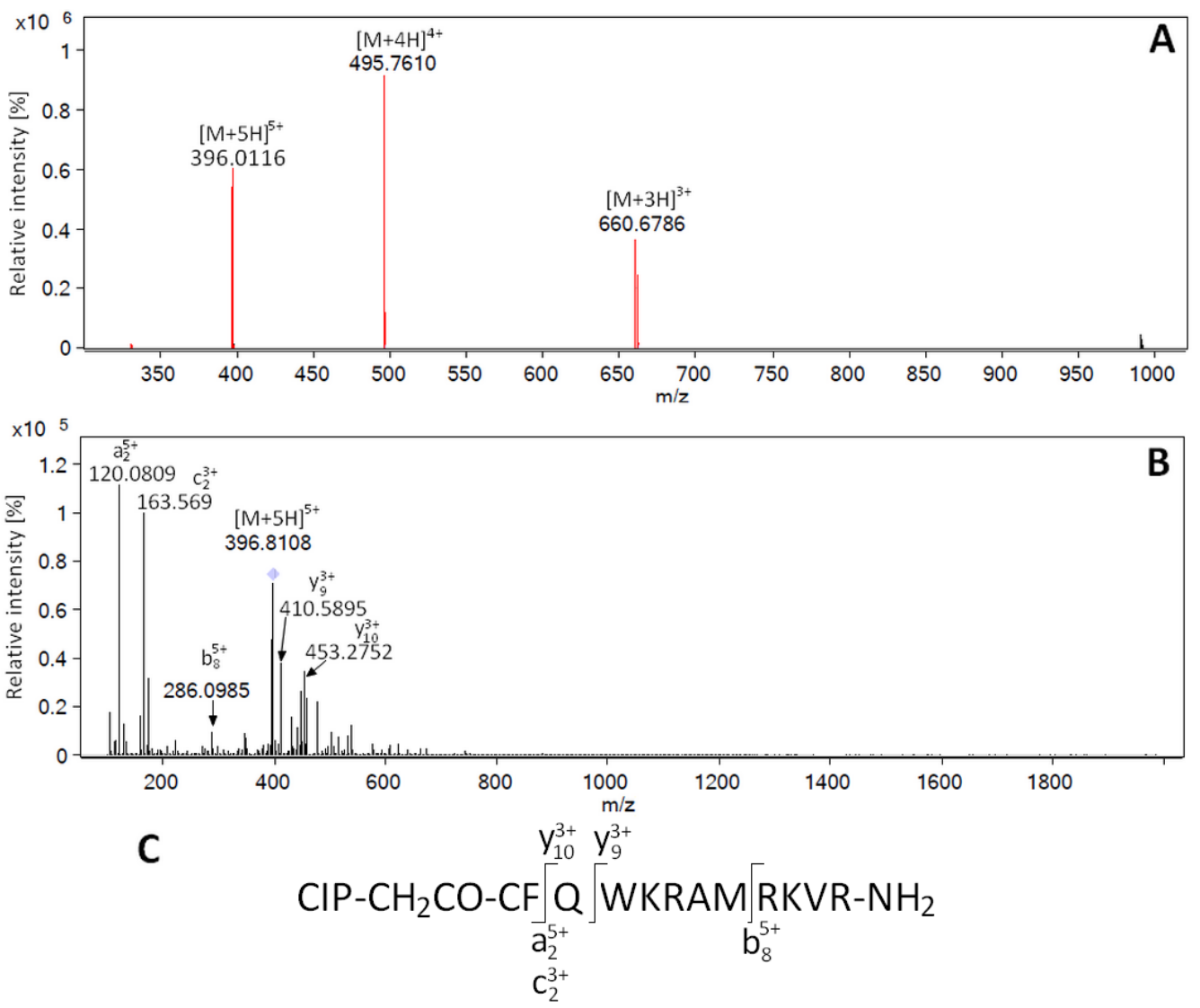
3. CIP-Cys-S-S-HLopt2-NH 2 (III)


C

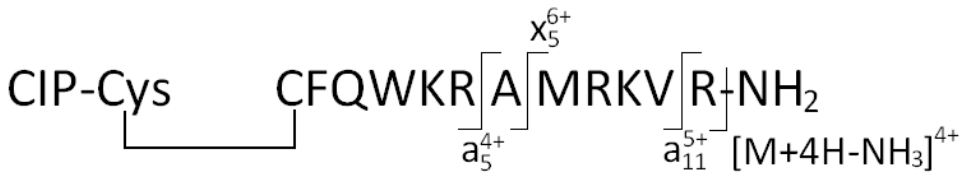

4. FLC-HLopt2-NH 2 (IV)
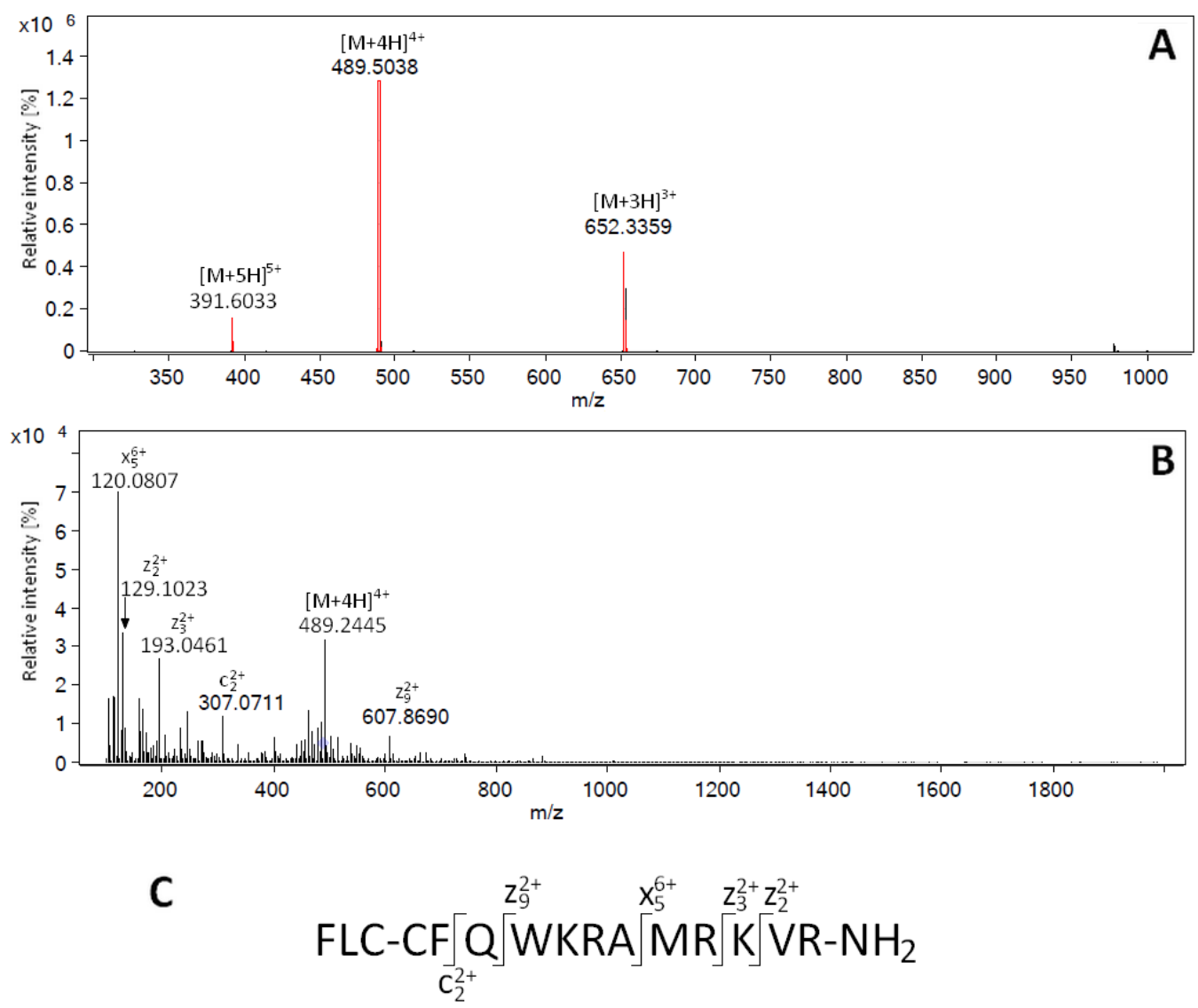
5. CIP-Cys-S-S-Cf-HLopt2 (V)
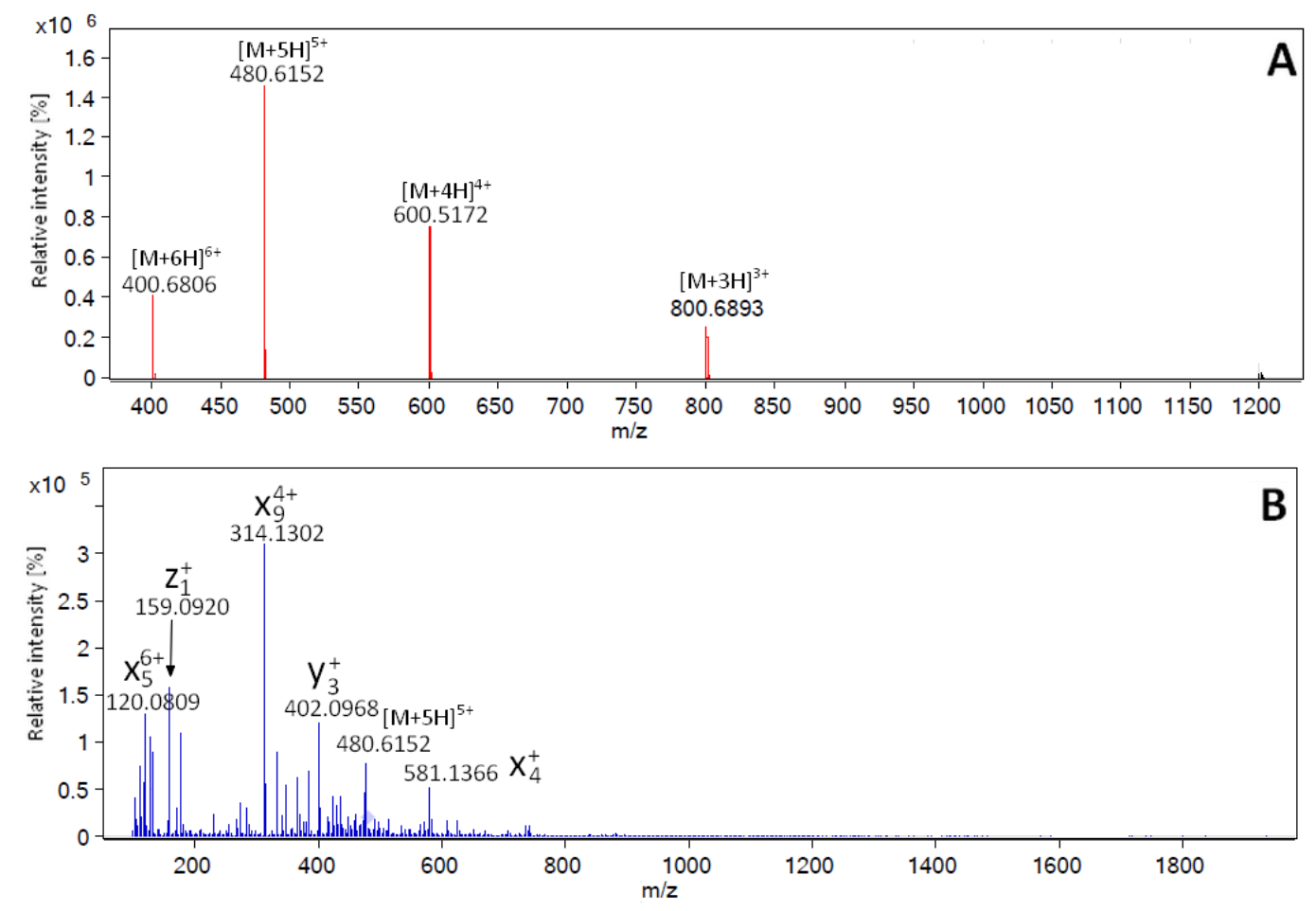

C

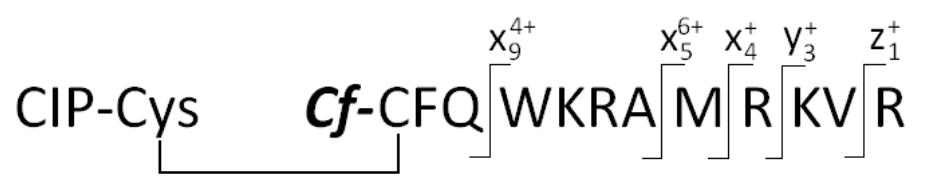

Figure S2. ESI-MS spectrum of protonated peptide conjugates (I-V) (A) and ESI-MS/MS spectra of peptide conjugates precursor ions (B), cleavage sites of peptide conjugates (C).

Synthesis of Levofloxacin and Ciprofloxacin-based Conjugates. Conjugates I-III and V were synthesized according to the methodology described previously. ${ }^{2}$ In the case of the conjugate I, LVX (Sigma-Aldrich), $N, N^{\prime}$-diisopropylcarbodiimide (DIC), and $N, N^{\prime}$ diisopropylethylamine (3 equiv. of each) were dissolved in DMF/DCM (v/v; 1/1), added to SPPS vessel with peptidyl-resin, and stirred for $90 \mathrm{~min}$. Coupling was repeated three times to increase its efficiency. Submonomeric approach ${ }^{4}$ was applied to synthesize CIP-based conjugate (II). The solution of bromoacetic acid and DIC ( 5 equiv. of each) in DCM/DMF (1/1; $\mathrm{v} / \mathrm{v}$ ) was added to peptidyl-resin and shaken in SPPS vessel for $30 \mathrm{~min}$. The coupling of ciprofloxacin (Sigma-Aldrich) to the peptidyl-resin was achieved by adding the suspension of CIP (1.5 equiv.) and $\mathrm{K}_{2} \mathrm{CO}_{3}$ (1.2 equiv.) in DCM/DMF. The reaction mixture was stirred for 24 $\mathrm{h}$ at room temperature. The procedure was repeated twice. Finally, the conjugates were cleaved from the resin as described before. The disulfide bridge formation between CIP and peptide was preceded by the coupling of the antibiotic to the Cys derivative. Boc-Cys(Npys)-OSu was obtained in the reaction of Boc-Cys(Npys)-OH (Bachem) with $N$-hydroxysuccinimide in the presence of $N, N^{\prime}$-dicyclohexylcarbodiimide (DCC) used as the coupling reagent. In the next 
step, CIP (66 mg, $0.2 \mathrm{mmol})$ in $5 \mathrm{~mL}$ DMF/DCM (3/2; v/v) was added to the solution of BocCys(Npys)-OSu (94 mg, $0.2 \mathrm{mmol}$ ) in $3 \mathrm{~mL}$ of DMF. The reaction mixture was stirred overnight. The solvent was removed in vacuo and the product was treated several times with the ether (containing 10\% DCM) to wash out the unreacted ester. The Boc protecting group was removed by TFA ( $5 \mathrm{~mL}, 15 \mathrm{~min}$ at room temperature). The solution was concentrated in vacuo, then the remaining material was dissolved in water and lyophilized. The chemical structure of Cys(Npys)-CIP was confirmed by NMR (Figure S3). HLopt2- $\mathrm{NH}_{2}$ (45 mg, 0.03 $\mathrm{mmol})$ or $\boldsymbol{C} \boldsymbol{f}$-HLopt2 (61 mg, $0.03 \mathrm{mmol})$ was dissolved in $4 \mathrm{~mL} \mathrm{DMF/DCM} \mathrm{(3/1;} \mathrm{v/v)} \mathrm{and}$ Cys(Npys)-CIP (35 mg, $0.06 \mathrm{mmol}$ ) was added. The mixture was stirred overnight at room temperature. The progress of the reaction was monitored by analytical HPLC. After $24 \mathrm{~h}$, the solvent was removed in vacuo, the derivative was purified by semi-preparative HPLC.

${ }^{1} \mathrm{H}$, zTOCSY, ROESY and gHSQCAD NMR experiments, from standard Varian library, were run in DMSO- $\mathrm{d}_{6}$ solvent, using Varian Unity Inova $500 \mathrm{MHz}$ spectrometer. ${ }^{1} \mathrm{H}$ and ${ }^{13} \mathrm{C}$ chemical shifts scales were calibrated against residual solvent signals (2.50 and $39.5 \mathrm{ppm})$. Spin lock time was set to 80 and 300 ms for zTOCSY and ROESY sequences, respectively.

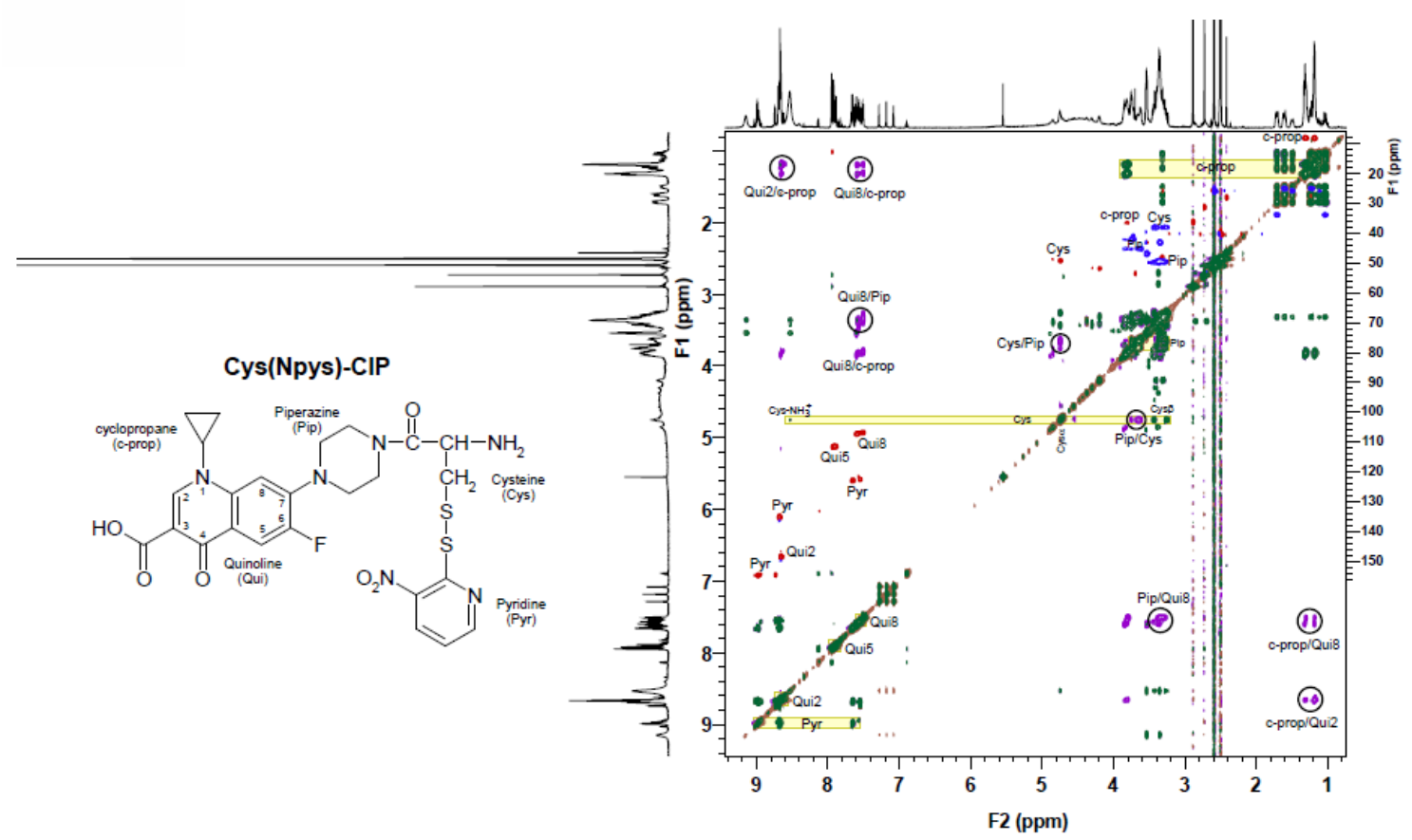

Figure S3. Superposition of three 2D NMR spectra of Cys(Npys)-CIP: TOCSY (green correlations, ROESY (purple correlations) and gHSQC (red correlations - $\mathrm{CH}$ group and blue $\mathrm{CH}_{2}$ group).

Synthesis of Fluconazole-Based Conjugates. The FLC-based conjugate was synthesized applying the method described in our work ${ }^{2}$ (Figure S4). FLC derivative (FLC-COOH) was manually attached to the peptidyl-resin using a coupling mixture, composed of: FLC-COOH 
(80 mg, $0.22 \mathrm{mmol}$ ), TBTU (71 mg, $0.22 \mathrm{mmol}$ ), Oxyme (31 mg, $0.22 \mathrm{mmol}$ ), and DIPEA (77 $\mu \mathrm{L}, 0.44 \mathrm{mmol})$. All reagents dissolved in $8 \mathrm{~mL}$ of DMF:DCM (1/1; v/v) were added to SPPS vessel with peptidyl resin (300 mg; loading $\left.0.24 \mathrm{mmolg}^{-1}\right)$, and stirred for $24 \mathrm{~h}$. The efficiency of the coupling reaction was monitored every $4-6 \mathrm{~h}$ using the chloranil test. In case of a positive test, acylation was repeated. Usually $48-72 \mathrm{~h}$ was required to complete the coupling. The conjugate was cleaved from the resin as described above. The crude product was purified on Beckman Gold System (Beckman, USA) equipped with RP Supelco Discovery BIO, Wide Pore C8, $10 \mathrm{~mm}$ column $(10 \times 250 \mathrm{~mm}$, Sigma Aldrich). The solvent systems were $0.1 \%$ TFA in water (A) and $80 \%$ acetonitrile in A (B). Linear gradient from 10 to $30 \%$ B for 30 min, flow rate $5.6 \mathrm{mLmin}^{-1}$, monitored at $226 \mathrm{~nm}$ was used. The product was verified by analytical HPLC and MALDI-TOF MS as described above.
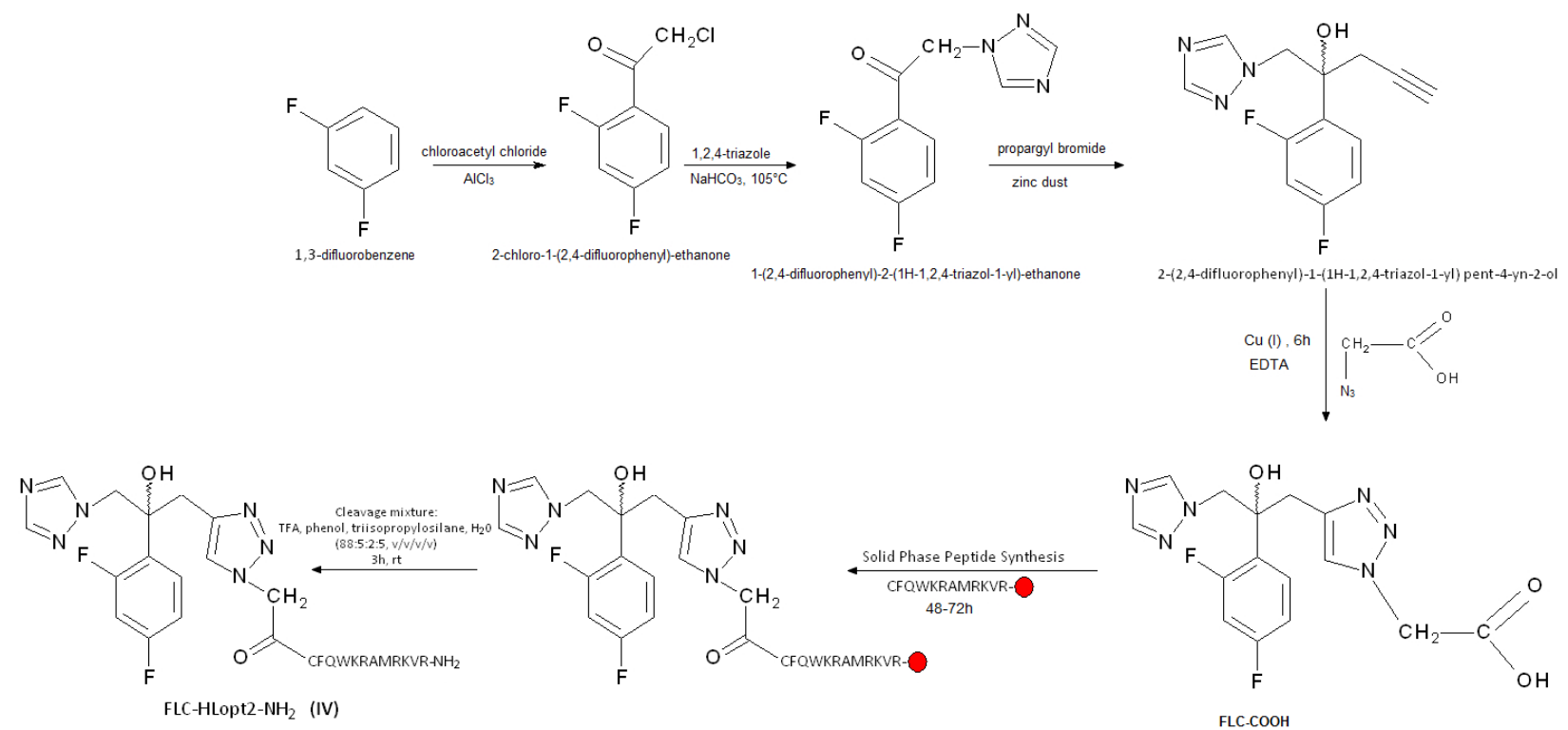

Figure S4. Synthesis of fluconazole-based conjugate IV.

Serum Stability Studies. Human serum from male plasma (Sigma-Aldrich) was prepared for the assay as referred previously. ${ }^{5}$ Experimental details of the stability in human serum studies for conjugates and constituent peptides were described in our previous papers. ${ }^{1,2}$

Microorganisms Strains and Growth Conditions. Biological experiments were performed with the following strains: C. albicans ATCC 10231, C. glabrata DSM 11226, C. krusei DSM 6128, clinical isolate of $C$. tropicalis, E.coli ATCC 25922, P. aeruginosa ATCC 27853, S. aureus ATCC 25923, S. epidermidis ATCC 12228, B. subtilis ATCC 6633, B. cereus PCM 
2003. Before the experiments, the yeast strains were cultured on YPD agar plates $(1 \%(\mathrm{w} / \mathrm{v})$ yeast extract, $2 \%(\mathrm{w} / \mathrm{v})$ peptone, $2 \%(\mathrm{w} / \mathrm{v})$ glucose, $2 \%(\mathrm{w} / \mathrm{v})$ agar) in $30^{\circ} \mathrm{C}$ and bacterial strains on LA (Luria-Bertani agar; $1 \%(\mathrm{w} / \mathrm{v})$ tryptone, $1 \%(\mathrm{w} / \mathrm{v}) \mathrm{NaCl}, 0.5 \%(\mathrm{w} / \mathrm{v})$ yeast extract, $2 \%$ agar) plates in $37^{\circ} \mathrm{C}$ for $16-24 \mathrm{~h}$.

Antifungal Activity Assay. The antifungal activity was assessed by the serial two-fold dilution method, with the usage of 96-well microtiter plates, in buffered RPMI-1640 medium. Exact conditions of the test are given in the CLSI recommendations (M27-A3 document, Clinical Laboratory Standards Institute 2008). The end-point readouts were determined spectrophotometrically at $660 \mathrm{~nm}$ wavelength with a microplate reader (Spark, Tecan). The lowest concentration that prevented the growth of microorganisms was assigned as MIC, while the lowest drug concentration that caused at least $50 \%$ reduction of growth compared to the drug-free control was assigned as $\mathrm{MIC}_{50}$.

Antibacterial Activity Assay. The antibacterial activity was established in three different growth media: Mueller Hinton broth (MHB), brain-heart infusion (BHI), and peptone (BP). Determinations of antibacterial activity of the tested compounds in MHB were performed using a serial two-fold dilution method in 96-well microtiter plates according to CLSI recommendations, described in M07-A10 document. The MIC and MIC $_{50}$ values were defined as described above for the antifungal activity assay. In the case of activity determinations in $\mathrm{BHI}_{1 / 100}$ and $1 \% \mathrm{~PB}$, cells were first grown overnight in $3.4 \%$ BHI. The next day the culture was refreshed in BHI for $2 \mathrm{~h}$. Cells were washed with PBS and adjusted to $6 \times 10^{5}$ cells $\mathrm{mL}^{-1}$ in diluted $\mathrm{BHI}\left(\mathrm{BHI}_{1 / 100}\right)$ or $1 \% \mathrm{BP}$. The tested compounds were serially two-fold diluted in 96well plates in appropriate medium $\left(\mathrm{BHI}_{\mathrm{dil}}\right.$ or $\left.1 \% \mathrm{BP}\right)$ and the cell suspension was added (final cell density $3 \times 10^{5}$ cells $\mathrm{mL}^{-1}$ ). After $2 \mathrm{~h}$ incubation at $37^{\circ} \mathrm{C}, 5 \mu \mathrm{L}$ from each well were dropped on LA plates. Both microtitration plates and LA plates were further incubated at $37^{\circ} \mathrm{C}$ for $20 \mathrm{~h}$. The concentration of the compound corresponding to the dilution at which $\geq 99.9 \%$ killing of the inoculum was obtained (no growth within the drop) was defined as the MMC value. The $\mathrm{MIC}_{50}$ value was defined as the concentration of the compound corresponding to the dilution at the microtitration plate at which the absorbance at $600 \mathrm{~nm}$ was reduced to at least $50 \%$ of that of the untreated inoculum.

Killing Kinetics. S. aureus ATCC 25923 cells were refreshed on LA plates. The cell suspension density was adjusted to $10^{8}$ cells $\mathrm{mL}^{-1}$ and further 100 -fold diluted in $\mathrm{BHI}_{1 / 100}$ or $1 \% \mathrm{BP}$. The concentrations of the tested compounds were prepared as twice higher than the final ones in appropriate medium and mixed in 1:1 ratio with cell suspensions. Immediately after inoculation 
and after 10, 20, 30, 60, 120, and 1200 minutes of incubation $\left(37^{\circ} \mathrm{C}, 180 \mathrm{rpm}\right)$, the samples were taken, serially diluted, and plated on LA. After further $20 \mathrm{~h}$, the CFUmL ${ }^{-1}$ value was determined.

\section{Cellular Uptake of Fluorescently Labeled Conjugate (III) and Its Constituent Peptide.} Uptake of fluorescently tagged CIP-Cys-S-S-C -HLopt2 conjugate (V), as well as its constituent peptide $\boldsymbol{C} \boldsymbol{f}$-HLopt2, by $S$. aureus and $C$. albicans was observed using fluorescence microscopy. Exact conditions were previously described. ${ }^{1,2}$ The cells were exposed to the action of fluorescently labelled compounds (final concentration 16 and $63 \mu \mathrm{gmL}^{-1}$ for S. aureus respectively and $250 \mu \mathrm{gmL}^{-1}$ for $C$. albicans) for 10 , 30, or 60 minutes. Yeast cells were additionally stained with Hoechst $33342\left(10 \mu \mathrm{gmL}^{-1}\right)$. Images were acquired with Olympus IX83 fluorescence microscope equipped with a $60 \times$ oil-immersion lens under green and blue light excitation.

Determination of Cytotoxicity. The cytotoxicity of the conjugates and its constituents was determined for three mammalian cell lines: HEK 293 (human embryonic kidney), Hep G2 (human liver cancer), and LLC-PK1 (normal, epithelial, adherent kidney proximal tubule cells isolated from kidney of 3-4 weeks old male pig) — all purchased from ATCC (American Type Culture Collection). Cell culture media and their components (penicillin, streptomycin, and FBS (Fetal Bovine Serum, Ref 35-015-CV)) were obtained from Corning. CIP and LVX were dissolved in sterile water acidified with hydrochloric acid, while FLC in DMSO.

Multiwell (96-well) plates were seeded at $7 \times 10^{3}$ cells/well in DMEM (HEK 293), MEM (Hep G2) or Medium 199 (LLC-PK1). Culture media were enriched with FBS (10\% or 7.5\% for Medium 199), $2 \mathrm{mM} \mathrm{L-glutamine,} \mathrm{and} \mathrm{antibiotics} \mathrm{(penicillin} 62.6 \mu \mathrm{gmL}^{-1}$ and streptomycin $\left.40.0 \mu \mathrm{gmL}^{-1}\right)$. Cells were incubated with the studied compounds for $72 \mathrm{~h}$ at $37{ }^{\circ} \mathrm{C}$ and $95 \% / 5 \%$ $\mathrm{CO}_{2}$ or $10 \% \mathrm{CO}_{2}$ (HEK 293) atmosphere. Finally, MTT in the amount of $20 \mu \mathrm{L}\left(4 \mathrm{mgmL}^{-1}\right.$ in PBS) was added to each well and plates were further incubated for $2-3 \mathrm{~h}$ at $37^{\circ} \mathrm{C}$. To each well, $150 \mu \mathrm{L}$ of DMSO was added and absorbance was measured using a multiwell plate reader at $\lambda$ $=540 \mathrm{~nm}$. Cell proliferation was determined compared to non-treated cells (\% control). All experiments were performed at least three times independently, each in triplicate.

Hemolytic activity. Blood samples remained after CBC tests were kindly provided by Regional Center for Blood Donation and Blood Treatment in Gdańsk. Erythrocytes were prepared according to Evans et al. ${ }^{6}$ Lysis assays were performed in 96-well plates. 1\% Triton X-100 solution was used as a positive control and PBS solution as a negative control. Tested compounds were serially diluted in PBS in $100-1.6 \mu \mathrm{gmL}^{-1}$ concentration range. After addition 
of the erythrocytes, the plates were incubated at $37^{\circ} \mathrm{C}$ for $1 \mathrm{~h}$ and centrifuged $(500 \times \mathrm{g}, 5 \mathrm{~min})$. $100 \mu \mathrm{L}$ of the supernatant was transferred to the new microtitration plates. Absorbance was measured at $540 \mathrm{~nm}$. All the experiments were performed in biological triplicates.

Stability Studies of Conjugates III and V and their Constituent Peptides in S. aureus Cells. Cell culture of $S$. aureus ATCC 25923 was refreshed on solid LA overnight $\left(37^{\circ} \mathrm{C}\right)$. The next day, cell suspensions were prepared in LB liquid medium, and after about 2 to 3 hours (logarithmic growth phase) the tested compounds were added at concentrations of $16 \mu \mathrm{gmL}^{-1}$ (CIP-Cys-S-S-HLopt2-NH 2 (III) and CIP-Cys-S-S-Cf-HLopt2 (V)) and $62.5 \mu$ gmL $^{-1}$ (HLopt2$\mathrm{NH}_{2}$ and $\boldsymbol{C} \boldsymbol{f}$-HLopt2) (MIC90) in a volume of $1 \mathrm{~mL}$. The cultures were continued overnight (37 ${ }^{\circ} \mathrm{C}, 180 \mathrm{rpm}$ ). The next day $1 \mathrm{~mL}$ of cell cultures were transferred to $2 \mathrm{~mL}$ tubes and centrifuged (12 $000 \mathrm{rpm}, 1 \mathrm{~min}, 4^{\circ} \mathrm{C}$ ) (from this moment the samples were kept on ice). The supernatant was discarded and the pellet was suspended in $0.5 \mathrm{~mL}$ of PBS. Zirconia beads (A \& A Biotechnology) and $350 \mu \mathrm{L}$ lysis buffer (Bioline) were added to the samples. The tubes were shaken on a BeadBeater device to break the cell wall $(3 \times 20 \mathrm{~s})$. The suspension was transferred to new tubes and $8.5 \mu \mathrm{L}$ of Protease Inhibitor Cocktail (100 x concentrated, Fermentas) was added. The tubes were centrifuged $\left(12000 \mathrm{rpm}, 20 \mathrm{~min}, 4{ }^{\circ} \mathrm{C}\right)$. The supernatant was transferred to new tubes and stored at $-20{ }^{\circ} \mathrm{C}$ until the MS analysis. Before MS analyses, the samples were desalted using ZipTip ${ }^{\circledR}$ C18 Pipette Tips (Merck Millipore Ltd) according to the manufacturer's protocol and subjected to a MALDI-TOF MS analysis (MALDI TOF/TOF 5800+ spectrometer, AB SCIEX). The ratio of CIP-Cys and HLopt2- $\mathrm{NH}_{2}$ to conjugate III in S. aureus cell lysate was determined by LC-MS with the use of a Shimadzu Nexera X2 UHPLC system equipped with a mass spectrometry detector (Shimadzu, LCMS-2020). The chromatography was performed on Phenomenex Aeris PEPTIDE XB-C18 column $(150 \times 2.1 \mathrm{~mm}, 3.6 \mu \mathrm{m}$ particle size). The column temperature was maintained at $40{ }^{\circ} \mathrm{C}$ and the flow rate was $0.3 \mathrm{mLmin}^{-1}$. The mobile phase consisted of $0.1 \% \mathrm{FA}+0.05 \% \mathrm{TFA}$ in $\mathrm{ACN}$ (solvent $\mathrm{A}$ ) and $0.1 \% \mathrm{FA}+0.05 \%$ TFA in water (solvent B). Chromatographic separation was carried out using a gradient method $15-60 \%$ of solvent A for $15 \mathrm{~min}$. The automatic sampler was maintained at $4{ }^{\circ} \mathrm{C}$ and the injection volume was $25 \mu \mathrm{L}$. The compounds in question were detected and analyzed by ESIMS detector operated in the positive ionization mode with the use of the selected ion monitoring mode (SIM). The capillary voltage was set at $5000 \mathrm{~V}$, source temperature was $300{ }^{\circ} \mathrm{C}$, desolvation temperature was $250{ }^{\circ} \mathrm{C}$, nebulizing gas flow rate was $1.51 \mathrm{~N}_{2} \mathrm{~min}^{-1}$ and drying gas flow rate was $151 \mathrm{~N}_{2} \mathrm{~min}^{-1}$. LC-MS chromatograms were recorded for selected $\mathrm{m} / \mathrm{z}$ ions: 434.25 (target ion $[\mathrm{M}+\mathrm{H}]^{+}$characteristic for CIP-Cys); 536.95 (target ion $[\mathrm{M}+3 \mathrm{H}]^{3+}$ characteristic for HLopt2- $\mathrm{NH}_{2}$; as well as 680.95 (target ion $[\mathrm{M}+3 \mathrm{H}]^{3+}$ characteristic for conjugate III. The ratio 
of CIP-Cys and HLopt2- $\mathrm{NH}_{2}$ to conjugate III was estimated based on the integration of the peak areas on LC-MS chromatograms recorded for target ions. 


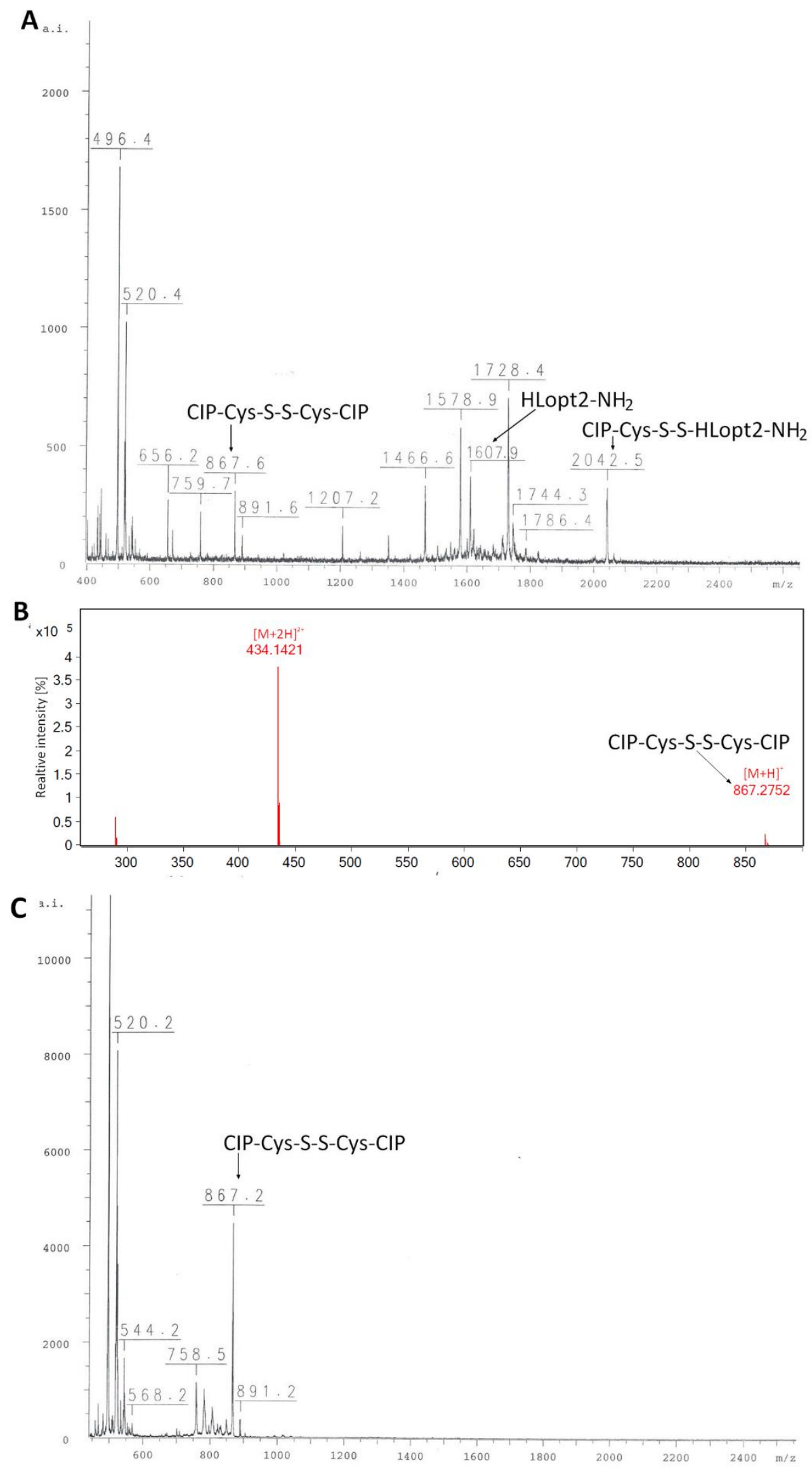

Figure S5. MS analysis of conjugate III after incubation in human serum (A) at $0 \mathrm{~h},(\mathrm{~B})$ at $1 \mathrm{~h}$ and $(\mathrm{C})$ after $2 \mathrm{~h}$ of incubation. Analyses were performed using MALDI MS (A and C) and LCMS (ESI) (B). 


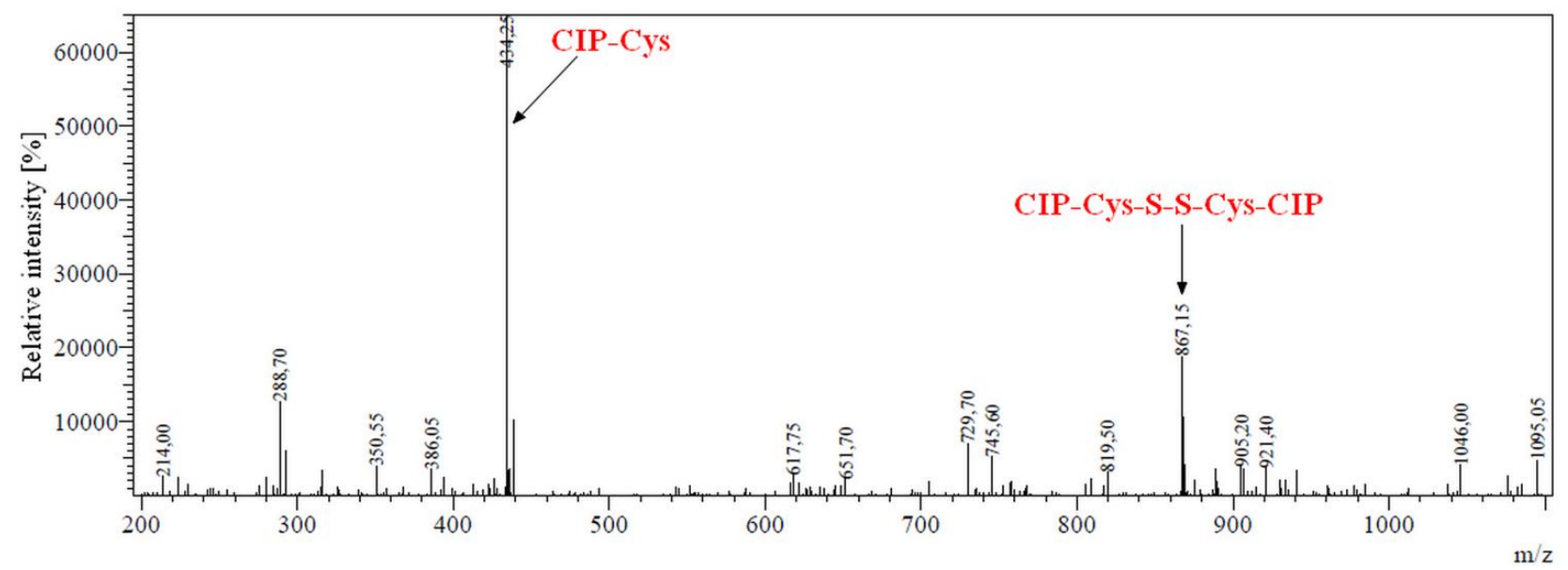

Figure S6. ESI-MS spectrum of CIP-Cys. 


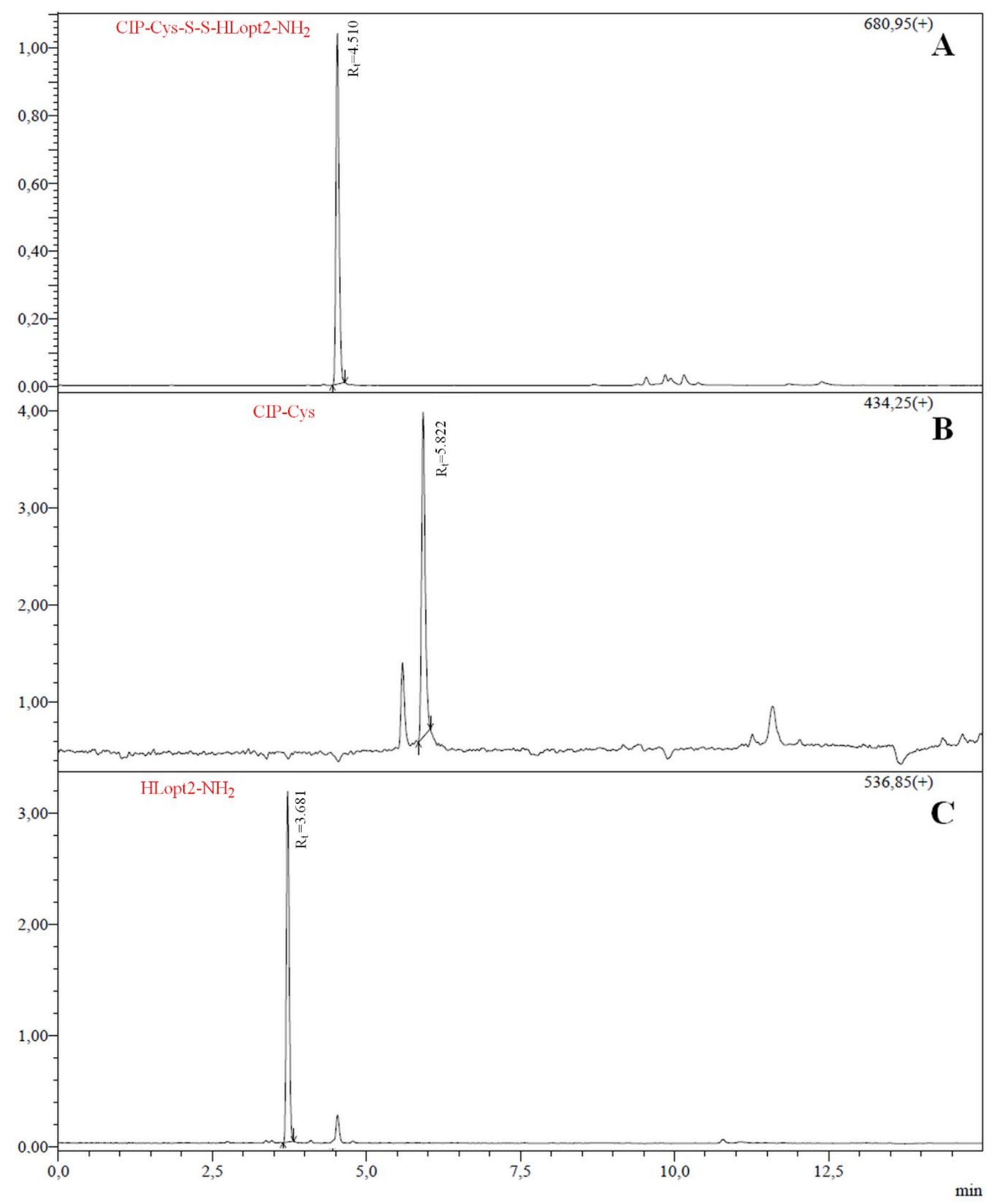

Figure S7. MS analysis of mixture of the conjugate III and its constituents. Signals were recorded at $\mathrm{m} / \mathrm{z} 680.95(\mathrm{~A}), 434.25$ (B) and $536.85(\mathrm{C})$, that correspond to molecular ions of CIP-Cys-S-S-HLopt2-NH 2 (III) $\left([\mathrm{M}+3 \mathrm{H}]^{3+}\right)$, CIP-Cys $\left([\mathrm{M}+\mathrm{H}]^{+}\right)$and HLopt2-NH $2\left([\mathrm{M}+3 \mathrm{H}]^{3+}\right)$, respectively. 




Figure S8. MS analysis of conjugate III incubated for $2 \mathrm{~h}$ with supernatant obtained after cell culture of S. aureus. Signals were recorded at m/z 536.85 (A), 680.95 (B) and 434.25 (C), corresponding to molecular ions of HLopt2- $\mathrm{NH}_{2}\left([\mathrm{M}+3 \mathrm{H}]^{3+}\right)$, CIP-Cys-S-S-HLopt2-NH 2 (III) $\left([\mathrm{M}+3 \mathrm{H}]^{3+}\right)$ and CIP-Cys $\left([\mathrm{M}+\mathrm{H}]^{+}\right)$, respectively. 


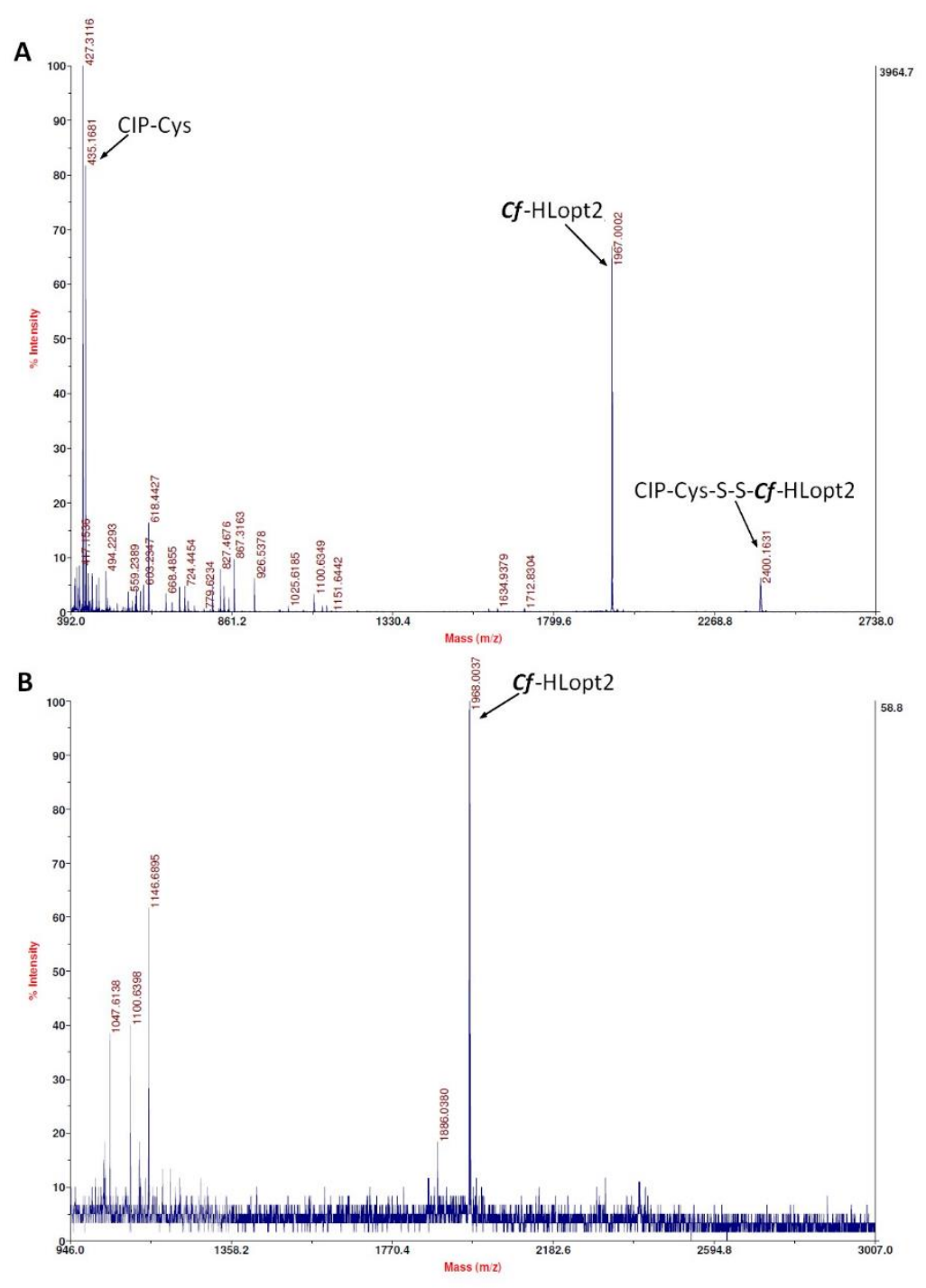

Figure S9. MS analysis of S. aureus cell lysate after incubation with the conjugate $\mathbf{V}$ (A) and its constituent peptide $\boldsymbol{C} \boldsymbol{f}$-HLopt2 (B).

\section{REFERENCES}

(1) Ptaszyńska, N., Gucwa, K., Łęgowska, A., Dębowski, D., Gitlin-Domagalska, A., Lica, J., Heldt, M., Martynow, D., Olszewski, M., Milewski, S., Ng, T. B., Rolka, K. (2018) Antimicrobial Activity of Chimera Peptides Composed of Human Neutrophil Peptide 1 (HNP-1) Truncated Analogues and Bovine Lactoferrampin. Bioconjug. Chem. 29, 30603071.

(2) Ptaszyńska, N., Olkiewicz, K., Okońska, J., Gucwa, K., Łęgowska, A., GitlinDomagalska, A., Dębowski, D., Lica, J., Heldt, M., Milewski, S., Ng, T. B., Rolka, K. (2019) Peptide Conjugates of Lactoferricin Analogues and Antimicrobials-Design, Chemical Synthesis, and Evaluation of Antimicrobial Activity and Mammalian Cytotoxicity. Peptides 117, 170079.

(3) Filipowicz, M., Ptaszyńska, N., Olkiewicz, K., Dębowski, D., Ćwikłowska, K., Burster, T., Pikuła, M., Krzystyniak, A., Łęgowska, A., Rolka, K. (2017) Spliced Analogues of Trypsin Inhibitor SFTI-1 and Their Application for Tracing Proteolysis and Delivery of Cargos inside the Cells. Biopolymers 108, e22988. 
(4) Simon, R. J., Kania, R. S., Zuckermann, R. N., Huebner, V. D., Jewell, D. A., Banville, S., Ng, S., Wang, L., Rosenberg, S., Marlowe, C. K., Pellmeyer, D. C., Tan, R., Frankel, A. D., Santi, D. V., Cohen, F. E., Bartlett, P. A. (1992) Peptoids: A Modular Approach to Drug Discovery. Proc. Natl. Acad. Sci. U. S. A. 89, 9367-9371.

(5) Chan, L. Y., Gunasekera, S., Henriques, S. T., Worth, N. F., Le, S.-J., Clark, R. J., Campbell, J. H., Craik, D. J., Daly, N. L. (2011) Engineering Pro-Angiogenic Peptides Using Stable, Disulfide-Rich Cyclic Scaffolds. Blood 118, 6709-6717.

(6) Evans, B. C., Nelson, C. E., Yu, S. S., Beavers, K. R., Kim, A. J., Li, H., Nelson, H. M., Giorgio, T. D., Duvall, C. L. (2013) Ex Vivo Red Blood Cell Hemolysis Assay for the Evaluation of PH-Responsive Endosomolytic Agents for Cytosolic Delivery of Biomacromolecular Drugs. J. Vis. Exp. e50166. 